Covered in: ERIH PLUS, CEEOL, Index Copernicus, CrossRef, CrossCheck, J-Gate, Google Scholar, Ideas RePeC, Econpapers, Socionet, KVK, WorldCat.

\section{Metal Detecting as Contemporary Artistic Research Method. Educational Values and Ethical Issues}

\section{Mihai Ionuț RUSEN1}

${ }^{1} \mathrm{PhD}$, Lecturer, National University of Arts, Bucharest, Romania.
Abstract: Metal detecting became a major issue for cultural environment, over intense debates for and against. Already regulated in western countries and making its contribution to cultural and scientific studies, is still fiercely debated in Eastern European countries. Usually classified as outdoor hobby or leisure activity, metal detecting, although incomplete and inadequately legislated, has proven to be a cultural and scientific vector with great potential for participatory research and democratic access to cutting-edge technology. The centennial anniversary of First World War highlighted the major social, cultural and mainly educational impact of metal detecting opportunities of bringing to light countless artifacts and situations which described the human dimensions and personal dramas of people trapped in both major conflicts of 20 th century. Besides undeniable educational values, when practiced by responsible and trained metal detectorists, inherent ethical issues arise in some contexts and situations. The article addresses the potential of metal detecting as contemporary artistic research method, within the related creative activities applied to recovered artifacts and collected data: classifications, photographic investigations, potential as sculptural objects and artistic installations. During the last decade, Eastern European metal detectorists became aware that democratization and public access to this technology offers the opportunity of participative research and regulated access to historical anthroposphere. Applications of this technology are multiple, within research areas of cultural environment. The method has great potential for educational fields and interactive teaching in arts and humanities.

Keywords: metal detecting; artistic research; visual arts; ethics; sculptural objects.

How to cite: Rusen, M. I. (2019). Metal Detecting as Contemporary Artistic Research Method. Educational Values and Ethical Issues. Logos Universality Mentality Education Novelty: Philosophy \& Humanistic Sciences, 7(2), 32-48. doi: 10.18662/lumenphs/25 


\section{Introduction}

Metal detectors and metal detecting has a lot in common with both world wars from the 20th century. Although invented at the end of the 19th and refined in design and applications throughout the 20th century, it was the World War II that contributed the most to the development of a portable, handheld device that was able to successfully identify landmines and solved a great military tactical problem: to clear a path through a mine field that drastically limits any military maneuvers. It should be also mentioned that during the interwar period, various metal detecting devices were used in cultural and scientific situations, and for purposes strangely similar to the contemporary research methods of metal detecting: recovery of archeological artifacts from an underwater site, scientific explorations in Antarctica, clearing the sites of unexploded bombs and artillery shells from World War I. Although commercially available since the early 1930s, only starting with the 60 's, after invention and development of transistor, manufacturers were able to produce lighter, handheld portable detectors with smaller battery packs than military versions of WW II, operating on vacuum tubes and separate batteries backpack. All this is happening in the western world, behind the Iron Curtain metal detectors exists, but only as military or other specialized versions, under strict state control. Private ownership of a metal detector is strictly forbidden. In the West, the cultural context of the 60's is extremely favorable: individual freedoms, enough spare time for leisure activities, affordability of the device, interest in local history, individual weekend explorations of rural areas, etc. It is also the time when the less favorable, public, common terminology of metal detecting is established, most probably by the media headlines: treasure hunting and treasure hunters, hobbyists, artifact seekers, site looters and even worst denomination.

Metal detecting is a world-wide trend already established in the European context for many decades. The scientific approach to metal detectorists is relatively new, and limited to local or national specifics. Also the legislative systems trying to regulate metal detecting usually led to blockages and difficult situations, actually having adverse effects. (Thomas, 2016: 14)

In fact, the World War 1 sites were looted for decades, especially during the interwar period, by locals and random by-passers, who explored the area and took any artifacts they could find for home use or memorabilia. Contemporary metal detecting is still a complex approach, within a legal 
context not quite regulated, due to contradictory laws and excessive bureaucracy. Responsible and dedicated detectorists performs dedicated investigation within these sites, driven by cultural projects purposes although collecting war memorabilia with market value is a constant purpose: the activity of metal detecting is not free of costs, expenditures for outdoor activity, equipment and transportation could be significant.

The range of a century old artifacts exposed to decay is a highly critical moment for decision and opportunity to be collected or not. Most of them were mass produced, from raw materials available at the time and within ersatz, procedures; they are substitutes, resulting from privations of war. This itself is a research topic and survey for contemporary metal detecting: design, use, presence, archeological and aesthetic values of ersatr. military artifacts within historical context. To collect these artifacts is highly advisable, due to their current state of decay which will become irreversible in just a few decades. As a result, many objects, some of them rare and hard to find even in military museum's collections, will be lost forever: ersatz bayonets, metal water bottles, belt buckles and countless other artifacts significant for the individual narrative and dramas of the battle sites.

From a strictly scientific point of view, the vast majority of artifacts gathered and collected by metal detecting in war sites have no archaeological value. They were usually mass produced, in industrial quantities, sometimes by millions. Therefore a small elite of detectorists acquired professional expertise exceeding that of museographers, being able to specify if certain artifacts are pre-war or were manufactured early or late in the war, if are ersatz type replacements and what units were using them. On certain occasions, a little bit of CSI/crime scene investigations methods, doubled by intuition and expertise reveal narrative and facts of real historical value, in contradiction with previous confused or official versions over the events.

Also the post-communist Romanian public experience with metal detecting is mostly negative due to overlapping with illegal treasure hunting by smuggled metal detectors within archaeological reservations; these shady activities started in the 1990's, being protected and even generated by corruption from the high levels of Romanian governments: only to be mentioned the shady story of the looted Dacian gold bracelets from the Sarmizegetusa archaeological site and reservation. Insistently requested by archeologists, a law to prohibit the metal detecting in Romania was seen like the ultimate solution to protect the archaeological heritage. However, such a law is still avoided because it could actually aggravate any situation. (Ganciu, 2018: 448) 
Contemporary metal detecting has many applications within cultural and scientific context of today, as democratic access to technology, participative research and direct educational purposes over modern history public perception. One interdisciplinary application of metal detecting, which is also the topic of this article is the artistic research method of investigation, pursuant of at least two ways outputs: educational values of artifacts and their visual documentation, and creative investigations over potential as contemporary sculptural objects, due to their design, uses, implied narrative, historical and archaeological status, perceived and translated within contemporary sculptural language. Everything comes at a cost, and not just passion and dedication. Although classified as leisure activity with specific benefits, metal detecting usually implies serious efforts and expenses. (Ferguson, 2013: 5)

Method of research. Artistic research methods applied to activities and investigative processes of metal detecting and subsequent creative approaches and products. Interdisciplinary perspectives over educational values of specific military artifacts that are searched for, recovered, archived and collected. Casual ethical issues concerning the procedures of searching, recovery and processing of such artifacts. Contemporary cultural values of artistic experiments, creativity and interpretations applied to specific artifacts attainable only through metal detecting technology.

\section{Military artifacts and the aesthetic qualities}

There is a close connection and cultural analogy between Paul Virilio's approach to Atlantic Wall concrete bunkers and contemporary fascination of metal detecting with World War I and II artifacts collection from all over available battlefields. Yet unlike any other war-time artifacts, the bunkers of Atlantic wall are mainly above ground and exposed to public view. The first to notice and explore the architectural aesthetics, archaeological and anthropological dimension of these brutalist volumes was Paul Virilio, and his groundbreaking Bunker Archeology: in our opinion, one of the first studies within the contemporary landmarks of artistic research. At that moment, the public perception was profoundly altered by the fresh memories about the war and Nazi ideology, the humiliation and suffering of occupation. This book suddenly introduces the perfect examples of brutalist, massive raw concrete modern bunkers into the cultural circuit of ideas about architectural creativity, the postmodern concept of the monument as a ruin or sculptural value as land art. Based on the formal analogies and the cultural and archaeological references of the ancient architectural traditions, Paul 
Virilio invent a new cultural and artistic perception on the landmarks of military architecture of the $20^{\text {th }}$ century: the artistic research approach. (Virilio, 1994: 11)

There are still strong debates in France whether the bunkers should be declared and maintained as part of national heritage; however, they carry an aesthetic and cognitive load that has transformed them into postmodern landmarks of brutalist raw concrete sculpture, including the land art movement. Even technically, these bunkers are closer to the sculptural object than to the architectural structure: basically concrete boxes, don't have foundations due to necessity to minimize direct or nearby explosions and their reverberation, so they actually float on the insertion site - sand or soil - what keeps them horizontally is their own center of gravity. Due to camouflage reason, landscape integration and shells deflection, all corners and edges are carefully rounded, embrasures are carefully fretted (in fact casted) in complex patterns, sending straight to Eduardo Chillida's massive forged iron sculptures. Some bunkers are already transformed into contemporary sculpture projects (Second World War bunker 599, The Netherlands) or even integrated for housing as part of beachfront villas. In the context of the contemporary urban landscape that surrounds them, their presence is strange but very aesthetic. On the same wavelength as Paul Virilio, regarding the unexpected aesthetic qualities of military artifacts, is Jean-Louis Cohen, although he also first considers the area of architecture and design of World War 2. Paul Virilio's seminars at that time, along with the publication of his first articles on the Atlantic Wall in Architecture Principe, came as a shock for me, for they proposed to raise the bunkers and military buildings of Nari Germany, which I considered to be utterly excluded from the field of architecture, into objects of technical and aesthetic analysis. (Cohen, 2011: 9)

By extrapolation, some of Cohen's references on aesthetics can be also applied to specific artifacts recovered during metal detecting surveys over any world wars sites. Obviously, military artifacts have aesthetic qualities regardless their condition, brand new or dug outs; being usually over-designed and over-engineered due to multitude of tasks and situations they had to support, this knowledge investment and forethought are able to generate beauty, aesthetics, even fascinations from collectors. There is nothing new about beauty and aesthetics on weapons and military artifacts, before industrial production, different levels of embellishment to military equipment were common. The perfect example is that bronze canons and bells were fabricated in the same foundries, by the same artisans, during the Renaissance and even later. Urban military artifacts of architectural dimensions, like the antiaircraft towers from major German cities are even 
today extremely visible and aesthetic by design, probably due to their second, defensive purpose as public bombing shelters. While the construction of bunkers was generally carried out by the Organization Todt or public works companies, it nonetheless involved architects as well. One of the most visible components was the construction of Flacktürme, or antiaircraft towers, designed by the architect Friederich Tamms, a student of Heinrich Tessenow and Hans Poelzig. (...) The theme of bunkers appealed to the imagination of a wide range of architects with varying poetic and visionary sensibilities. (Cohen, 2011: 227)

Ignored or forgotten during the post-war period, they proved practically indestructible so were repurposed, based on the same monumental and aesthetic presence, as community landmarks and urban service providers: antenna for cellular phones, city Aquarium, art storages, energy storage, nightclubs and businesses. Within their new, contemporary context, the urban presence of these former military artifacts is more aesthetic than ever, generated by the fortress-like, brutalist cast concrete industrial appearance. (...) only the very large can become monumental, and the constructions of industrial architecture, even though they are often thought of as great, cannot achieve this state as long as they no continue to serve profane ends. It is only when they are in a state of ruin, once they no longer retain their utilitarian side, that they can come to produce a monumental effect. (Cohen, 2011: 385)

The same aesthetic dimensions of cast concrete military artifacts of defensive architecture could be suggested within both famous and finally useless defensive systems: Maginot Line and Atlantic Wall, although Cohen deny any connections between architectural styles and national identities. The clear contrasts between the fluid fortifications of the Maginot Line and the prismatic bunkers of the Atlantic Wall are doubtlessly better explained by looking to the kinds of combat that designs anticipated rather than some Germanic predilection for sharp silhouettes as opposed to a French sense of flush contours. (Cohen, 2011: 14)

The aesthetic dimension of military artifacts includes decay and destruction, sometimes both of them. The same thing happens to any kind of artifact that passed through war, destruction and subsequent decay, above or below the ground. Significant urban landmarks, landscapes or buildings severely damaged by war are transformed, more or less often, into war memorials, as an anthropological answer of communities or nations to death and destruction. The concept works identically to dug outs artifacts from battle sites: lost, abandoned or discarded, decaying below or at ground level for many decades or a full century; once unearthed, they recover and expose their contents, aesthetics included, still open to be investigated, understood, explored and sometimes creatively interpreted. Even during the war itself, the aesthetic potential of ruins and devastated landscapes had been pointed out by architects on 
Metal Detecting as Contemporary Artistic Research Method. Educational Values ... Mihai Ionuţ RUSEN

both sides, who sought a certain poetic promise in them. (...) Most people look at the charred ruins of this war with the disgust for things that were useful and are now no use. Only very few can detach themselves from utilitarian, bumanitarian and educational viewpoints to see ruins as objects picturesque and pleasingly horrifying. (Cohen, 2011: 383)

Within the Romanian cultural environment, metal detecting is relatively new in the sense of conducting investigative projects, everything expanding just after 2010. Although this is a solitary activity or teamed up in small and cohesive groups, social media, online dedicated groups and the passion for this type of field research has also favored the participatory dimensions of cultural metal detecting projects. Some practioners accede and join various research projects by providing artifact images, research documentation, any information and data, maintaining a complex dialogue on the topics. Regardless of the participatory levels of metal detecting research projects, the individual example of original cultural projects and high quality artistic research is essential. The perfect example and textbook case study is the Underground project, developed between 2014-2015 by Bogdan Gîrbovan \& Michele Bressan. Both graduates of Photo-Video Department of National University of Arts from Bucharest, trained in development and conduct of artistic projects, together they set the standards and modus operandi for what we call now metal detecting artistic research projects. Obviously, their personal projects and especially the standards of artistic research have evolved within the participatory context of a wider group, with various areas of expertise yet highly dedicated to metal detecting investigations. The journey and the entire process of searching gradually acquired the quality of a performative ritual, in which the sound of the metal detector, the silence of nature and the sound of digging created a sonic rbythm and a dynamics of movement with their own contributions to the intensity of the artistic process. What at first was playful enthusiasm gradually transformed into emotion and a sense of responsibility in respect of the unearthing of buried objects belonging to people no longer with us. This increasing sense of responsibility felt by the artists towards the memory of the objects and the people is visible from their careful archiving of everything they found. (Gîrbovan, 2018: 98-102)

Right after the cleaning and restoration stage, the studio area of the project begins, when the artistic and documentary investigation can be carried out. Cleaning is always a time consuming and also a delicate process due to a century old decay (or at least seven decades for World War 2 artifacts) gathered in outdoor sites, constantly exposed to the weather, beneath or above ground. Basic restoration is required to stop subsequent degradation, especially for leather, wood and textile artifacts, using even commercially available products and substances. The studio stage of a metal 
detecting artistic research project refers to extended photographic documentation of unearthed artifacts, yet from both scientific and also artistic, creative points of view. Bogdan Gîrbovan and Michele Bressan are professional photographers, trained in Visual Arts, constantly aware about the artistic potential of their investigative project. Based on a photographic concept, they were able to choose what to stage, to retain or discard for the moment, what to transmit and to investigate photographically from the visual narratives of artifacts; from simple object presence to a certain aura of a postmodern museum. Once unearthed, the objects found are photographed digitally in the studio, where they are completely decontextualised, being placed against a white background and viewed from above. The downwards perspective is thus retained, analogous to how they were found in the earth, but now in an entirely different context. In the forest, in the trenches where they were found, the objects were just as unique, but seemed far more modest in appearance, given how they were camouflaged in earth. In the studio, however, they suddenly appear hypnotic, iconic and monumental. There is no longer any indication of scale and they assert themselves in their own right, instantly becoming museum pieces and demanding the right to exist in the world, independent of context. (Gîrbovan, 2018: 104)

\section{Critical and ethical issues of contemporary metal detecting activity}

It seems obvious that the current rate of the metal detecting phenomenon could almost exhaust the Romanian sites from first and second World War, in a decade or two at most. However, this estimation is only valid for the superficial layer of the sites, down to a depth of maximum $50 \mathrm{~cm}$. After 2010, when metal detectors became accessible and legal in Romania, the first authorized detectorists used to find artifacts at point blank range, at the ground level, only covered by dust, grass or leaves. As the hobby gained momentum, access to artifacts became more and more difficult, the sites being explored in depth, depending on the technical capabilities of detectors. The evolution of those capabilities, in the sense of technology advance and price accessibility could greatly influence the rate of exhaustion within World War 1 and 2 sites with public access, especially in Eastern Europe. In some cases, the archeological context of the First World War sites is extremely complicated, because it overlaps, as in the case of Prabova Valley, with ancient sites described by a less studied branch of research in Romania: the mountain archeology. There are some random reports about antique bronze artifacts, like the example of a Celtic ax found on the slope of a trench, apparently dug out and unnoticed or ignored by soldiers in 1916. Accidentally ransacked antique bronze artifacts could be 
many more in war sites but are passed over due to similarity of sound and numeric signal with the endless number of spent cartridge casings, usually ignored by detectorists. However, the historical context of World War 1 and 2 exists anyway, from sources sufficiently numerous to allow a slightly more relaxed approach to the current situations of battlefield metal detecting. Within this particular case, recovering, reporting and submitting the antiques bronze artifacts to archaeologists is the best case scenario to save them from destruction: weather exposure, acidity of shallow soil, etc. In fact, within these circumstances, metal detecting is the best case scenario to save any artifacts from certain destruction due to acidic rain and soil or extensive use of fertilizers (Dobat, 2013: 708)

Metal detecting is the perfect tool to identify accidents and incidents of history: lost artifacts, discarded or abandoned; in one word, fortuitous artifacts. In battlefield sites of World War 1 and 2, most artifacts are lost and abandoned, discarded, forming the garbage left behind by war, debris and detritus, although invested with a lot of emotional values, extremely impressive as by-products of human violence, narratives of suffering, distress and pain. This is also the highly favorable cultural context for artistic research projects mentioned above; the perfect situation to invest as cognitive vehicle the war artifacts not old enough to be traditional archaeological subjects but already fixed in collective memory and able to develop aesthetic values and creative interpretations and research. The extremely thorough research they conducted of the chosen locations and the related historical events drew Bogdan and Michele closer and closer to idea of art as an instrument of knowledge, as a means of revealing a truth and as a historical document. Probably the most important element of their endeavour is that of affording visibility to objects that would otherwise have remained hidden. However, the entry into the realm of the visible for these objects was also a traumatic process: some oxidize as soon as they were brought to the surface; others turn out to be dangerous. (Gîrbovan, 2018: 104-105)

\section{Metal detecting as method of artistic research}

The Project R.A.P.I. (Romanian Archaeological Photography Index) inserts within the Romanian cultural environment the interdisciplinary approach of artistic research through the technology of metal detecting as multifunctional investigative tool. The situation of artifacts dug outs from World War 1 sites and the context of 1914 Centennial was a match made in heaven, and it has significantly enhanced the positive perception of the results in the cultural environment, particularly for the Visual Arts. Although the cultural context was much more complex regarding the personal research routes, the 
project started a cultural trend, active today. How did the project started? Michele Bressan: In fact, we begin from a fantasy. I had this idea with the metal detector since I was in a residence in Paris. I was passionate about history, war, conflict as a situation that generates other individual situations, all the capillaries of a war situation. And the best way to get very close to these things was the metal detector, as a tool that would somehow allow you to pinch this historical vein.(...) Bogdan Girbovan: I found it fascinating that you go out with an instrument that is ringing (that is all it does, it only makes sounds, lower or higher) and you capture images, below the ground. Moreover, I thought about gravity: no one escapes it. Neither we, nor the trees, nor the forests. Everything is going where? In the ground. (DoR, 2016)

Besides the deliverable results of the project - the series of photos, cleaned and restored artifacts, publications, exhibitions, on-line texts and images, the field activities involved a great deal of resources and time, never perceived as such by the general public. Usually metal detecting means heavy outdoor activities in remote areas, walking tens of kilometers each day, spending on fuel and equipment and often going home empty-handed. In fact, the outdoor based research by seeking, detecting and dug outs activities also have an artistic value as performative approach of mapping the site and its landscape container.

In the same area of artistic research projects stands Zsolt Asztalos and his Fired but Unexploded video installation presented in Hungarian Pavilion of La Biennale di Veneria in 2013, an undisputed project solid anchored in the Visual Arts cultural environment and internationally acclaimed. The artist was given access to professional collection of World War 2 bombs and projectiles recovered and defused by the Hungarian Bomb Disposal Unit, he photographed and video recorded them, obviously choosing them according to aesthetic and concept criteria.

In fact, unexploded ammunition from both World Wars is a real issue even today, especially in former battle sites of Western Front, from both first and second world wars. The quantities of unexploded ammunitions left behind by wars are huge, being a constant presence and danger for the life of entire communities. However, there are two very interesting details of all these ammunitions: they are either unused or misfired. The misfired status is the most interesting for contemporary artistic research. The artistic research project of Zsolt Asztalos is entirely based on various misfired bombs and projectiles. In fact, no artifact was exposed directly, but only their visual icons, documented and included in the video installation. The artist was granted access only to study the collection of bombs and projectiles, to document them and record the images that were to form the work of art. Besides the video installation itself, the main 
deliverable research product of this artistic product is the catalogue, having the same importance as the work of art due to extensive presentation of concepts, working ideas and the cross-disciplinary approach of thematic and cultural context. In addition to the national commissioner and the curator, the texts of the catalogue are also the contribution of a bomb disposal expert, a mathematician and a poet/monk. Their expertise is obviously but creatively connected to the main topic: technology of ammunition and disposal of misfires, theory of probability and the divine grace. (soundslikevenice.wordpress.com)

The exhibition of Zsolt Asztalos is undoubtedly a special moment in the contemporary visual arts, a perfect match between the historical moment, the cultural context, a certain sort of morbid fascination from the general public for this kind of artifacts, the visibility of the Venice Biennale and not at least the open mindedness of the national jury. The time was also perfect for this prelude of the 1914 Centennial a sort of reference for artistic research projects that will mark the contemporary cultural landscape for the coming years, until 2018.

Metal detecting is a relatively new activity within the legal framework in Romania, having between five to ten years of expertise; the same range applies to commercial availability of metal detectors. In a natural way for the complexity of such an interdisciplinary activity, the ethical issues did not delay to appear, along with frictions regarding the rigidity of state authorities unable to react, adapt and evolve to metal detecting research activities. The ethical issues are real, due to extreme diversity of metal detectorists; Michele Bressan and Bogdan Gîrbovan were the first, as authors of R.A.P.I. (Romanian Archaeological Photography Index)/Underground Project, to realize the need for ethical approaches during any research involving the metal detector and field activities in war sites. Therefore, both artists' professional web pages (Bressan, 2014; Gîrbovan, 2014) contain the asterisk footnote which should become the core of any code of ethics for metal detecting research: the authorization of metal detector and the respect of legislation.

However, we have to be all aware about the pressure on World War 1 and 2 sites in Romania and Eastern Europe, either real or circumstantial. One solution to release this pressure is to approach and investigate new sites and areas, also from modern history, insufficiently studied but extremely important for post-war Eastern Europe: communism and Iron Curtain. Although still politically sensitive, metal detecting is the best solution to begin archaeological surveys of former prisons and detention camps from wartime and communist era, decommissioned garrisons and military installations, industrial archeology on decayed factories and industrial 
platforms, on famous socialist construction sites, or even probing sections of former city dumps closed decades ago. This is also a context where metal detecting is an inestimable and essential tool for any archaeology survey, the traditional method of shovel testing being useless comparative with systematic, fast and highly effective metal detecting investigation.

\section{The potential of human resources within metal detecting and the need for archaeological education}

Metal detecting world is a highly competitive and egocentric environment, although expressions like brotherbood of detectorists are common. Collaboration and accurate communication and exchange of useful information between metal detectorists are based on personal credibility, individual credentials, reliability, discretion and moral values. Ruthless treasure hunters, pirates, illicit and non-authorized detectorists are rejected by the community itself, finally acting lonely or in small, isolated groups: lonely wolfs, mavericks, predators; after all, an unfortunate social constant for any field of activity.

Although it has o short history in Romania, almost a decade as legal outdoor hobby, metal detecting is structured, as human resources, like a meritocracy, where the personal legend - the finds - and the years of sustained activity generate personalities, stars and leaders. Some of them shine on social media with daily or weekly posting of recently dug artifacts, fresh on the spot, even in situ. Financially powerful detectorists, with top jobs on private sector build impressive private collections of war artifacts, recovered from the sites or purchased from free market. Is predictable that in the near future some new, private museums will take by surprise a cultural environment stuck in traditionalism. However, is enough room for these concepts to evolve in modern, original ways, diametrically opposed to state driven centennial festivism. Some other personalities, stars and leaders of metal detecting prefer to stay in the shadow, as discreet professionals, due to their former, deeply unpleasant experiences with authorities and its bureaucratic rigmarole - especially when bodies of fallen soldiers are found, ammunitions, weapons or real treasure items. The contemporary status of metal detecting and its practitioners continue to be highly debatable due to lack of reliable information and bad communication mainly with the scientific community, especially the archaeologists. (Thomas, 2016: 141) 
Metal Detecting as Contemporary Artistic Research Method. Educational Values ... Mihai Ionuţ RUSEN

\section{Ethical issues of metal detecting}

It is undeniable that many activities of metal detecting have potential ethical issues, due to its interdisciplinary, transversal and liberal approaches to different sensitive topics: official history, traditional archeology, national mythologies, post-communist ways of thinking about the property over valuable, recovered heritage artifacts.

It is fascinating to detect and dig in war sites, excepting at least for two situations: live ammunition and, especially, bodies. The media cover of metal detecting is unfortunately specific for the tabloid press; in September 2017, British journalist Jack Losh (2017) has published the article Battlefield bounty bunters: the detectorists of Eastern Europe - Enthusiasts fuelled by vodka and nationalism are on the hunt for military memorabilia. Jack Losh joins a group of Poles, and meets the men trying to stop them. The main data of the article are not necessarily questionable, nor is the author's probity, the general atmosphere recognizable to any practitioner of metal detecting, as well as the characters, their clothes of choice, their personal backgrounds, motivations, even arguments and discourses.

Still, some issues have to be clarified; the group described here is not and never would be part of any mainstream, organized metal detecting movement. The area where this freelance group operates appears to be a border zone between Poland and former Soviet Union, where all authorities are usually concerned with smuggling and organized crime. Members of the group come from all social layers but the hard core consists of simple villagers from the area, having the skills, knowledge and lifetime experience to navigate the woods and wilderness for military artifacts from centuries of wars. Somewhat troubling is the discourse of some of them, with apparent psychological profiles of post-communist proletarians with right-wing tendencies on top of exacerbated nationalism - copiously quoted by the British journalist. As a result, the strange sense of foreseeing that far-right suspicions could do the most harm to metal detecting communities across the Europe. All in all, this article describes the weekend of a Männerbünde with the passion of metal detecting, in an area rich in history and military artifacts from countless conflicts. "The group gathers for one last beer, inspecting the weekend's haul. Besides shrapnel and cartridge cases, there are coins and military buttons from the $19^{\text {th }}$ century, a 1660s shilling, a bronze medallion from the Russian-Turkish war (1877-78), a Nazi map-reading instrument, and a handsome piece of silver. But they've not made that dynamite discovery that could earn a fortune and generate a legend. No problem, smiles Dariusz, shrugging his shoulders. We try again next weekend". (Losh, 2017) 
It is a working hypothesis and a possible conclusion of this article that metal detecting investigation, research and recovery of artifacts from first and Second World War sites could be considered as an exercise and practice to synchronize archaeology and contemporary cultural environment with the realities of metal detecting community. The obvious ethical issues have to be taken very seriously and must be made aware within a strict code of good practices and procedures assumed by metal detecting practitioners. There is also an emerging market for this kind of artifacts, usually translated and interpreted as reason and cause for looting and exhausting the sites. However, the market value of these artifacts is largely insignificant, being purchased by passionate collectors which actually save them from a near disappearance. Another issue that has to be upgraded about collected artifacts is the context - al metal detectorists keep detailed photographic evidences of their finds. If they would add as much as possible data to every image, large portions of context information would be available. Basically, a smart phone is the second tool of choice for detectorists, besides the detector itself, containing all the devices needed to thoroughly document an archaeologically level survey performed by a single or small group of detectorists. Four people are enough, specialist included, as we find out in September 2019, during an archaeological survey leaded by a National History Museum archaeologist, learning in one day a significant amount of good practices and procedures, multiplying by ten our field experience. The obvious solution for the contemporary controversies regarding metal detecting is the education and/through technology. By providing useful scientific data and information to archaeological environment could transform metal detectorists into auxiliary researchers, although the level of rigor and self-imposed discipline is mandatory. The basic research and data gathering technology is also available; the smart phone could decently cover the context in any survey, investigation, research and artifacts recovery involving metal detecting; photographic documentation in situ and after recovery, coordinates of the finds, open source applications to identify and save the route traveled, location, etc. The problem today is not that metal detectorist should become amateur archaeologists, but we should educated ourselves to extend our skills and concerns towards participative, citizens scientific approach to archaeological context and data gatherings, within the purpose of multiplying our knowledge and results of our work and passion. (Clark, 2013) 


\section{Conclusions}

The last decade brought an obvious trend in artistic research projects of immersive history and daring prospects over the recent past. The context of cultural environment favored this approach by the 1914 Centennial, along with a sort of imminence for the 1939 one, only two decades away from now. The same outside the box vision explains itself by the participatory approach of citizen science concept.

Metal detecting is about to become an educational vector in both ways, input and output towards the contemporary cultural environment. It generates education and knowledge via direct experience over recovered artifacts, through artistic research projects, themed exhibitions, participative projects, publications, social media, interdisciplinary archaeological survey teams and reenactment passionate. It also absorbs education and knowledge to evolve and adapt to contemporary ethics (Frunza, 2016; Huidu, 2019), mainly acquiring context and data collecting procedures from archaeologists or investing time, resources and activities in research concepts from contemporary cultural environment.

The great achievement of artistic research projects such as R.A.P.I. is the survey of the anthropic environment of $20^{\text {th }}$ century World Wars that brings an immersive experience within the real story, so far from the official, state festivist rhetoric.

From the beginning, the cold and tense relationship with the authorities is still maintained, although the signs of relieve have already appeared, through cooperation and joint activities with archaeologists, within interdisciplinary teams of field survey. The general public opinion on both sides is that the future means working together.

At the level of human resources, metal detecting environment created over the last decade a very interesting species of professionals in this field, with interdisciplinary skills and abilities ideal for $21^{\text {st }}$ century citizen research participative activities within cultural projects. In every country, metal detecting community already has its personalities of the field and even celebrities, with amazing level of expertise, who either shine on social media or prefer to stay in the shade due to their former, at least unpleasant experiences with authorities and their bureaucratic rigmarole, especially when bodies are found, ammunition or weapons, not to mentioned real treasure items. 


\section{Acknowledgements}

First I would like to thank Florin Burlacu, Gerald Iustin and Dan Constantinescu from Predeal, for their support, guidance and generosity within metal detecting activities. Special thanks to Pompiliu Alexandru, PhD Lecturer, Valahia University from Târgovisste, who contributed a great deal to my research.

\section{References}

Bressan, M. (2014). R.A.P.I. (Romanian Archaeological Photography Index), available at https://www.michelebressan.ro/R-A-P-I

Clark, S. (2013). Metal detecting and archaeological advocacy - Some observations and ideas from a detectorist. Day of Archaeology. Retrieved from https://www.dayofarchaeology.com/metal-detecting-and-archaeologicaladvocacy-some-observations-and-ideas-from-a-detectorist/

Cohen, J. L. (2011). Architecture in uniform - Designing and building for the Second World War. Paris, France, Éditions Hazan.

Dobat, A. S. (2013). Between rescue and research: an evaluation after 30 years of liberal metal detecting in archeological research and heritage practice in Denmark. European Journal of Archaeology, 16(4):704-725

DoR (2016). Tacu Irina and Lungu Adrian, From the ground. When you unearth and photograph combs, helmets, armaments and bones, where do you draw the line between art and archeology? Retrieved from https://www.dor.ro/din-pamantfragment-din-dor-23/.

Ferguson, N. (2013). Biting the bullet: the role of hobbyist metal detecting within battlefield archeology, Internet Archaeology, 33.

Frunză, A. (2016). Către o nouă expertiză etică: deconstruind valorile etice. Iasi, Romania: LUMEN.

Ganciu, I. (2018). Heritage for sale! The role of museums in promoting metal detecting and looting in Romania. Heritage, 2018, 1:437-452.

Gîrbovan, B. (2014). R.A.P.I Underground 2014 - 2015, available at https://girbovan.ro/01-r-a-p-i-underground-2014-2015/

Gîrbovan, B. (2018). Categorii/Categories. Bucharest, RO: Galeria Posibila

Huidu, A. (2019). Tailoring humans: The ethics of genetic engineering În A. Sandu, A. Frunză \& E. Unguru (Coords.), Ethics in research practice and innovation. Hershey, SUA: IGI Global. doi:10.4018/978-1-5225-6310-5

Losh, J. (2017). Battlefield bounty hunters: the detectorists of Eastern Europe. The Guardian. Retrieved from https://www.theguardian.com/global/2017/sep/17/battlefield-bountyhunters-in-polish-ww2-battlefields 
Metal Detecting as Contemporary Artistic Research Method. Educational Values ... Mihai Ionuț RUSEN

soundslikevenice.wordpress.com (2013). 55th International Art Exbibition - La

Biennale di Veneria - Zsolt ASZTALOS. Fired but unexploded.

Hungarian Pavilion. Retrieved from

https://soundslikevenice.wordpress.com/2013/05/27/zsolt-asztalos-firedbut-unexploded-hungarian-pavilion/

Thomas, S. (2016). The future of studying hobbyist metal detecting in Europe: A call for a transnational approach. Open Archaeology, 2(1).

Virilio, P. (1994). Bunker Archeology. New York, USA: Princeton Architectural Press 